\title{
A life skills intervention for school-going adolescents in India
} J Kaur, V P Joshith

\section{Abstract \\ Background}

Young people face many stressors in their day-to-day lives. Life skills programmes are designed to help young people to cope better with stressors and deal positively with difficult situations.

Aim

The major objective of the present study was to explore the effect of a life skills intervention on depression, anxiety and stress among adolescents in India.

\section{Methods}

The study followed a quasi-experimental research design using a multistage random sampling technique, and 970 adolescents were included in the study. The study was conducted in three phases. In the first phase, pre-testing was done using the Punjabi version of the Depression, anxiety and stress scale (DASS) to assess for depression, anxiety and stress among Indian adolescents. The life skills intervention was conducted during the second phase of the study, among students in class IX in Government Secondary Schools located in 11 districts of Punjab, India. Post-testing was done in the third phase, at the end of the life skills intervention. Analysis of covariance was conducted for data analysis.

\section{Conclusions}

The results of the study indicated that the life skills intervention was associated with a significant reduction of depression, anxiety and stress among the study participants. Our findings suggest that such life skill programs should be researched further, in view of integrating them into the school curriculum.

Key words: life skills intervention, depression, anxiety, stress, adolescents.

SL J Psychiatry 2021; 12(2): 22-27

\section{Introduction}

Adolescence is a critical period of transition from childhood to adulthood, which is characterized by rapid physiological changes and psycho-social maturation. This is a turning point in one's life, a period of increased potential but also of vulnerability. Some key issues and concerns observed among adolescents include, those relating to forming of self-image, managing emotions, building relationships, strengthening social skills, and dealing with peer pressure. Given the stage of their lives, adolescents are more prone to act impulsively and take risks. While many adolescents are able to deal effectively with challenges, some struggle and may experience psychological morbidity. Globally, one in seven in the adolescent age group has a mental disorder, which accounts for $13 \%$ of the global burden of disease (1). Depression, anxiety and behavioural disorders are important causes of illness and disability among adolescents, and suicide is the fourth leading cause of death among 15-19 year-olds (2).
The way in which an adolescent may respond to difficulties is decided by a host of factors, including their personality, psycho-social support received from those around them (particularly from parents, teachers and peers), and the life skills that they possess. Life skills intervention seek to empower youth to make responsible and healthy choices in their lives. International research suggests that youth with good competence skills have lower rates of substance use, depression, delinquency, and aggressive behaviours (3-4). Life skills training has been found to play a significant role in promoting mental health across varied population groups, and is reported to have a significant impact on happiness, and psychological and emotional well-being of individuals, thereby improving overall quality of life (5-14). Such life skills training programmes may also be effective in developing personality traits such as resilience, self-efficacy, and improving self-esteem (15-19). However, evidence from India is limited. The objective of this study is to examine the effect of a life skill intervention on depression, anxiety and stress among Indian adolescents. 


\section{Methods}

\section{Procedure and study participants}

This was a quasi-experimental study. Adolescents aged 14-16 years, studying in the ninth grade in Government Secondary Schools affiliated with the Punjab School Education Board (PSEB) in the Punjab state, India, were the study population. Out of the 22 districts in the Punjab state, 11 districts were randomly selected for inclusion in the study. From the each randomly selected district, a government secondary school was randomly selected from the list of schools, obtained from the District Education Officer. A total of 970 adolescents were selected for inclusion in the study, using multistage random sampling. The sample size was determined as per the table 4.3, considering the level of significance to be 0.01 and the margin of error is $5 \%(20)$. The mean age of the participants was 14.95 years. In each of the selected schools, section A was taken as the experimental group and section B as the control group. Matching of the experimental and control group was done in each of the selected schools on the basis of intelligence and socioeconomic status before the intervention. The experimental group comprised of 485 students (male $=264$; female $=221$ ) and the control group also comprised of 485 students (male $=251$; female $=235$ ).

Permission was obtained from relevant authorities and school principals prior to starting the study. Ethical approval was obtained from the Department of Education, Punjabi University, Patiala to conduct the study.

\section{Outcomes of interest and tools used}

The Depression, Anxiety and Stress Scale (DASS-42) was used to assess depression, anxiety and stress among adolescents (21). The depression, anxiety, stress scale (DASS) is a 42-item questionnaire which includes three self-report scales designed to measure the negative emotional states of depression, anxiety and stress. Each of the three scales contains 14 items, divided into subscales of 2-5 items with similar content. The Depression scale assesses for dysphoria, hopelessness, devaluation of life, self-deprecation, and lack of interest/involvement, anhedonia, and inertia. The anxiety scale assesses autonomic arousal, skeletal muscle effects, situational anxiety, and subjective experience of anxious affect. The Stress scale assesses difficulty relaxing, nervous arousal, and being easily upset/agitated, irritable/over-reactive and impatient. Respondents are asked to use 4-point severity/frequency scales to rate the extent to which they have experienced each state over the past week. For the present study, the authors prepared the Punjabi version of the DASS-42 by following a backward-forward translation procedure. The Cronbach's alpha of the translated scale was 0.89 , indicating good internal consistency.

\section{Development of the Life Skills Training Module}

The life skills intervention delivered in this study is an activity based programme especially designed for adolescents, which is participatory in nature. It includes the activities pertaining to ten core life skills viz. selfawareness, effective communication, inter-personal relationship, decision-making, problem-solving, creative thinking, critical thinking, empathy, coping with emotions and coping with stress $(1,20)$. The major techniques used to impart training are role play, small group activities, lectures and group discussions.

The life skills training module was prepared after referring to many different types of life skills training manuals available online and offline. The life skills activities were selected from the standardized life skills manuals, to suit to school students in India. The module was then reviewed by a group of experts in order to assess for relevance of the activities and to establish content validity.

\section{Procedure}

The study was conducted in three phases as described below:

\section{Phase I:}

During the pre-test, the investigator administered the Punjabi version of Depression, Anxiety and Stress Scale to Punjabi adolescents, within their respective school premises. The participants were approached in their class rooms, with prior permission from the District Education Officer (DEO) and principal of the school, along with the assistance of the class teachers concerned. The participants were informed about the purpose of the study and a rapport was established with the participants. They were requested to remain calm, follow the instructions and complete the scale. They had the freedom to report any matter (such as ambiguity in the items, confusions, etc.) to the researcher. They were assured that the information given by them would be kept confidential and would be used only for research purpose.

\section{Phase II:}

The life skills intervention was conducted among adolescents in the ninth grade, in class settings in the respective school premises. The life skills intervention program was carried out by the researcher, with the assistance of the class teacher and $\mathrm{PhD}$ research scholars from Department of Education, Punjabi University, Patiala. The life skills intervention was conducted for one and a half months ( 30 working days), in 30 sessions. Each session was conducted for 40 minutes. All sessions were activity based and participatory in nature. The major techniques used to impart training were role play, small group activities, lecture and group discussions. There 
was no intervention program given to the control group of school students, and they continued their usual education.

\section{Phase III:}

Post-testing was done immediately after completion of the life skills training program, using the same tool as used for the pretesting (the Punjabi version of DASS scale), and was conducted within the class premises with the help of the class teacher.

\section{Analysis and results}

To study the effectiveness of life skills intervention on depression, anxiety and stress among Indian adolescents, analysis of covariance (ANCOVA) was carried out on the post-test depression, anxiety and stress scores of adolescents, keeping pre-test scores as a covariate. Table 1 shows the means and SDs of depression, anxiety and stress scores of the students in the experimental and control groups pre and posttest.

In order to see whether life skills training had any significant effect on depression, anxiety and stress among adolescents, ANCOVA was employed on the depression, anxiety and stress scores of adolescents, keeping pre-test scores as covariate (Table 2).

Table 1. Means and SDs of the pre and post-test depression, anxiety and stress scores in the intervention and control group of adolescents

\begin{tabular}{|c|c|c|c|c|c|c|c|}
\hline \multirow[b]{2}{*}{ Variable } & \multirow[b]{2}{*}{ Stage } & \multicolumn{3}{|c|}{ Experimental Group } & \multicolumn{3}{|c|}{ Control Group } \\
\hline & & $\mathrm{N}$ & Mean & SD & $\mathrm{N}$ & Mean & SD \\
\hline \multirow[t]{2}{*}{ Depression } & Pre-test & 485 & 15.65 & 6.60 & 485 & 15.06 & 7.39 \\
\hline & Post-test & 485 & 11.94 & 6.01 & 485 & 13.43 & 6.73 \\
\hline \multirow[t]{2}{*}{ Anxiety } & Pre-test & 485 & 15.29 & 6.46 & 485 & 14.97 & 6.91 \\
\hline & Post-test & 485 & 11.88 & 5.66 & 485 & 13.05 & 6.30 \\
\hline \multirow[t]{2}{*}{ Stress } & Pre-test & 485 & 16.21 & 6.46 & 485 & 15.76 & 6.91 \\
\hline & Post-test & 485 & 12.37 & 5.62 & 485 & 14.72 & 6.39 \\
\hline
\end{tabular}

Table 2. Summary of analysis of covariance of depression, anxiety and stress among adolescents in the experimental and control groups

\begin{tabular}{|l|c|c|c|c|c|}
\hline Variable & Source & Sum of Squares & df & Mean Square & F-value \\
\hline \multirow{3}{*}{ Depression } & Pre-test & 15035.28 & 1 & 15035.28 & $596.88^{* *}$ \\
& Treatment & 327.03 & 1 & 327.03 & $12.98^{* *}$ \\
& Error & 24358.53 & 967 & 25.19 & \\
& Total & 39934.20 & 969 & & \\
\hline \multirow{3}{*}{ Anxiety } & Pre-test & 12207.92 & 1 & 12207.92 & $524.94^{* *}$ \\
& Treatment & 236.99 & 1 & 236.99 & $10.19^{* *}$ \\
& Error & 22488.61 & 967 & 23.26 & \\
& Total & 35023.31 & 969 & & $670.89 * *$ \\
Stress & Pre-test & 14363.82 & 1 & 14363.82 & $49.53^{* *}$ \\
& Treatment & 1060.39 & 1 & 1060.39 & 21.41 \\
\hline
\end{tabular}


The F-values, testing the significance of effect of life skill training on adjusted mean depression, stress and anxiety scores were 12.98, 10.19 and 49.53 respectively, which are significant at 0.01 level (Table 2 ). The results of post hoc analysis and the adjusted mean depression, anxiety and stress scores of adolescents of experimental and control groups along with pre and post-test mean scores are presented in table 3 . When considering the adjusted mean depression, anxiety and stress scores at post-test, all three were significantly lower in the experimental compared to the control groups.

\begin{tabular}{|c|c|c|c|c|c|c|}
\hline Variable & Group & $\mathrm{N}$ & $\begin{array}{c}\text { Pre-test } \\
\text { Mean }\end{array}$ & $\begin{array}{c}\text { Post-test } \\
\text { Mean }\end{array}$ & $\begin{array}{l}\text { Adjusted } \\
\text { Mean }\end{array}$ & t-value \\
\hline \multirow{3}{*}{ Depression } & Experimental & 485 & 15.65 & 11.94 & 12.10 & \\
\hline & Control & 485 & 15.06 & 13.43 & 13.26 & $2.83^{* *}$ \\
\hline & \multicolumn{2}{|c|}{ General Means } & 15.63 & 12.69 & 12.68 & \\
\hline \multirow{3}{*}{ Anxiety } & Experimental & 485 & 15.29 & 11.88 & 11.97 & \\
\hline & Control & 485 & 14.97 & 13.05 & 12.96 & $2.57^{* *}$ \\
\hline & \multicolumn{2}{|c|}{ General Means } & 15.13 & 12.47 & 12.47 & \\
\hline \multirow{3}{*}{ Stress } & Experimental & 485 & 16.21 & 12.37 & 12.50 & \\
\hline & Control & 485 & 15.76 & 14.72 & 14.59 & $5.41 * *$ \\
\hline & \multicolumn{2}{|c|}{ General Means } & 15.99 & 13.55 & 13.55 & \\
\hline
\end{tabular}

$* * \mathrm{p} \leq 0.01$

\section{Discussion}

The results of the study indicate that the life skills training provided in this study, was associated with reduction of features of anxiety and depression among adolescents in the study, and also with reduced stress levels. These results are in line with the findings of previous research, where life skills training has been found to have a significant effect on psychological issues such as stress, anxiety and depression across various population groups (22-25, 5-6). The findings of our study suggest life skills programmes could be introduced in schools to improve the psychological wellbeing of adolescents.

To make this viable and sustainable, such programs should be organized and supported alongside other educational programs, by the relevant authorities at school level $(26,27)$. Teachers could help by introducing life skills programs during their routine teaching, to enable young people to solve their problems and make their own decisions in an effective way. To do this, teachers should be provided with the knowledge and skills to impart life skill education to the adolescents. Practical issues, such as provision of appropriate time for such programs, should also be considered. Educational institutions can play an important role in the prevention of psycho-social stress, improving mental health and promoting healthy habits among students (28).

\section{Limitations}

The present study was conducted with government school students hailing from rural areas of the Punjab state in India. The study may need to further extended to private secondary school students from the urban areas, to make the results more generalizable. Qualitative research with stakeholders may help to evaluate how best to incorporate life skills education in school curriculum.

\section{Conclusions}

Given the importance of good mental health in modern societies and among young people, schools should consider incorporating life skill programs in their curriculum, to support the emotional development of adolescents. Based on findings on our study, it is recommended that life skills education should be made a priority and part of the school curriculum (6). It is also suggested that this area be further researched in the 
developing world, and more resources and training should be provided to teachers to create an enabling environment for teaching life skills to the adolescents.

\section{Acknowledgements}

The financial grant provided by University Grants Commission, New Delhi (India) for carrying out this research study is gratefully acknowledged.

J Kaur, Department of Education and Community Service, Punjabi University, Patiala, India

V P Joshith, School of Education, Central University of Kerala, India

Corresponding author: J Kaur

Email: mahal.jagpreet@gmail.com

http://orcid.org/0000-0003-0426-9448

\section{References}

1. World Health Organization. Life Skills Education for Children and Adolescents in Schools: Introduction and Guidelines to Facilitate the Development and Implementation of Life Skills, 2rev. Avaliable from: https:// apps.who.int/iris/handle/10665/63552 [Accessed $29^{\text {th }}$ November, 2021].

2. World Health Organization. Adolescent mental health. Available from: https:/www.who.int/news-room/factsheets/detail/adolescent-mental-health [Accessed $29^{\text {th }}$ November, 2021].

3. Weissberg RP, Borton HA, Shriver TP. The Social Competence Promotion Programme for Young Adolescents. In GW Albee, TP. Gullotta et al. (Eds.) Primary Prevention Works. Issues in Children's and Families' Lives. Thousand Oaks, CA, USA: Sage Publications, Inc. 1997; 268-90.

4. Zins JE, Elias MJ, Greenberg MT, Weissberg RP. Promoting Social and Emotional Competence in Children. In K. Minke and G. Bear (Eds.) Preventing School Problems-Promoting School Success: Strategies and Programs that Work Bethesd, M.D. National Association of School Psychologists 2000; 71-99.

5. Barkhordar A, Hasan A, Safdar A. A study of the effects of Life Skills Training on Students self-concepts, Motivation and Mental health. International Journal of Current Science 2016; 19(1): 113-18.

6. Jamali S, Sekineh S, Hamid SN, Amir HG, Sima B, KellyAnn A. The Effect of Life Skills Training on Mental Health of Iranian Middle School Students: A Preliminary Study. Iranian Journal of Psychiatry 2016; 11(4); 269-72.
7. Lee MJ, Wu WC, Chang HC, Chen HJ, Lin WS, Feng JY, Lee TSH. Effectiveness of a school-based life skills program on emotional regulation and depression among elementary school students: A randomized study. Children and Youth Services Review 2020; 118.

8. Kumara HV. Impact of life skills training on academic stress, depression and happiness among adolescent students. Journal of Xi'an University of Architecture and Technology 2020; 12(4): 2417-35.

9. Bazrafshan M, Delam H, Kaqvi E. The Importance of Life Skills Training in Preventing Addiction Recurrence between January and February 2020: A Narrative Review Article. J Health Sci Surveillance Sys. 2020; 8(2): 58-62.

10. Acharya S. Impact of Life Skills Training Programs for Handling Psycho-social Problems of Adolescents Students in Kalinga Institute of Social Science, Proceeding of $5^{\text {th }}$ International Conference on Life Skill Education. New Delhi: Excel India Publisher, 2014.

11. Amrei MT, Farahani A. The effectiveness of training life skills on happiness of students. World Scientific News. 2016; 46: 276-86.

12. Irannezhad S. Effectiveness of life-skills training on the mental health of $2^{\text {nd }}$ grade female High School students in Bam-Iran. Bali Medical Journal 2017; 6(3): 583.

13. Khademi MJ, Abedi MR, Pourmeidani S. Effectiveness of quality of life training on happiness among Isfahan blind girls. International Journal of Educational and Psychological Researches 2017; 3: 29-35.

14. Narasimharaju. Impact of life skills training program on general well-being of high school students. International Journal of Indian Psychology 2020; 8(2): 1160-66. DIP:18.01.133/20200802, DOI:10.25215/0802.133

15. Shwetha BC. The Role of Life Skills Training in Developing Emotional Maturity and Stress Resilience among Adolescents. The International Journal of Indian Psychology 2015; 2(4): 193-203.

16. Barkhordar A, Hasan A, Safdar A. A study of the effects of Life Skills Training on Students self-concepts, Motivation and Mental health. International Journal of Current Science 2016; 19(1): 113-18.

17. Assadi GR, Nasiri VS, Nesayan A. The effect of life skills training on resiliency and adaptation in adolescents with physical disabilities. Journal of Pediatric Nursing 2017; 3(3): 20-5.

18. Sharma S, Arora K, Chandrashekhar. Evaluation of a training program for life skills education and financial literacy to community health workers in India: a quasiexperimental study. BMC Health Services Research 2021; 21(46): https://doi.org/10.1186/s12913-020-06025-4

19. Kaur J, Kaur M. Effectiveness of life skills intervention on adolescents. Research and Reflections on Education 2021; 19(3): 13-16. 
20. Sansanwal DN. (2020). Research methodology and applied statistics. Delhi: Shipra Publications; 2020.

21. Lovibond SH, Lovibond PF. Manual for the Depression Anxiety Stress Scales (2 $2^{\text {nd }}$ ed.). Sydney: Psychology Foundation of Australia; 1995.

22. Azargoon H, Motlay MA, Dareke M. Effectiveness of Family Training and Life Skills on Caring Chronic Mental Disorders in an Iranian Population. Psychology, Society and Education 2013; 5(1): 77-90.

23. Bahrami GG, Molojabari F. The Effect of Training Life Skills on Mental Health of Mothers having Exceptional Children. European Journal of Experimental Biology 2013; 3(2): 1-5.

24. Gatab TA, Jeludar S, Ghajari AV, Jeludar ZA. Effects of the education of life skills on the reduction of mentalbehavioral disorders of depression, anxiety, stress in students. European Psychiatry 2013; 28: 1.

25. Mohammadi SY, Nejad Y. The Impact of Life Skills Training and Family Economic Conditions on the Subscale Social Dysfunctions of Mental Health: A Study among
Students of Bousher's High Schools in Iran. Proceedings of the $5^{\text {th }}$ International Conference on Life Skills Education. New Delhi: Excel India Publisher 2014; 196-204.

26. Yankey T, Biswas UN. Life Skills Training as an Effective Intervention Strategy to Reduce Stress among Tibetan Refugee Adolescents. Journal of Refugee Studies 2012; 25(4): 514-36. DOI: https://doi.org/10.1093/jrs/fer056.

27. Habibi Z, Somayeh T, Hasan S, Abbass A. Effectiveness of Stress Management Skill Training on the Depression, Anxiety and Stress Levels in Drug Addicts after Drug Withdrawal. International Journal of High Risk Behaviors and Addiction 2013; 12(2): 82-6.

DOI: $10.5812 /$ ijhrba. 10695.

28. Maddah, Diana, Saab, Youssra, Safadi, Hani, Abi Farraj, Nermine, Hassan, Zeinab, Turner, Sophia, Echeverri, Lina, Alami, Nael H, Kababian-Khasholian, Tamar, Salameh, Pascale. The first life skills intervention to enhance wellbeing amongst university students in the Arab world: 'Khotwa' pilot study. Health Psychology Open, 2021. Available from: https://sage.altmetric.com/details/ 107796983 [Accessed 30 $0^{\text {th }}$ November, 2021]. 